\title{
An experimental investigation of patterns of parasitism at three spatial scales in an aphid-parasitoid system (Hymenoptera: Aphidiidae)
}

\author{
VOJTĚCH JAROŠÍK ${ }^{1 *}$ and LAURENT LAPCHIN ${ }^{2}$ \\ ${ }^{1}$ Charles University, Department of Zoology, Viničná 7, 12844 Prague 2, Czech Republic; e-mail: jarosik@mbox.cesnet.cz \\ ${ }^{2}$ INRA, Unité de Biologie des Populations, 37, Boulevard du Cap, 06600 Antibes, France
}

Key words. Aphidius colemani Viereck, Myzus persicae Sulzer, spatial density dependence, population regulation, biological control, foraging behaviour

\begin{abstract}
Density dependent host mortality in the interaction between the solitary endoparasitoid Aphidius colemani (Aphidiidae), and its host, the green peach aphid Myzus persicae, was examined on greenhouse peppers. The experimental approach attempted to eliminate spatial interdependence in the relationship between host density and host mortality by using different plants to measure parasitism at different spatial scales. Increasing host density at the plant scale caused a significant increase in the proportion of host mortality. However, at the shoot and leaf scale, increasing host density caused a significant decrease in host mortality. This may be one of the first experimental demonstrations of a switch from inverse to direct density dependence. The pattern is assumed to be a result of searching parasitoids using different cues at different spatial scales.
\end{abstract}

\section{INTRODUCTION}

Host-parasitoid interactions have been of widespread interest in ecology for many years, and their analyses have contributed to the elucidation of mechanisms that underpin population dynamics. However, the role of spatial components of parasitoid impacts on population dynamics in heterogeneous environments remains unresolved. Host mortality in the field caused by parasitoid attack may have one of three relationships with density (see Lessells, 1985; Stiling, 1987; Walde \& Murdoch, 1988):

1. directly density dependent when the risk of parasitism increases with host density;

2. inversely-density dependent when the risk decreases with increasing density;

3. density-independent or "domed" when maximum mortality occurs at intermediate densities.

How these modes of attack affect the dynamic stability of parasitoid-host systems is still not fully resolved (Murdoch \& Stewart-Oaten, 1989; Hochberg \& Lawton, 1990; Hassell et al., 1991; Pacala \& Hassell, 1991; Godfray \& Pacala, 1992; Ives, 1992; Murdoch et al., 1992; Taylor, 1993; Godfray et al., 1994; Rohani et al., 1994; Getz \& Mills, 1996). To resolve these issues requires that we be able to detect the population consequences of individual parasitoid behaviour (Heads \& Lawton, 1983; Lessells, 1985; Ayal, 1987), and this requires determination of the correct sampling units. The natural distribution of most parasitoid hosts is aggregated across a series of spatial scales (Hassell \& Southwood, 1978). As the searching behaviour of parasitoids is regarded as adaptive, parasitoids should be able to recognise those units of habitat that are more profitable to search than others (Stephens \&
Krebs, 1986). Furthermore, the degree of host mortality should depend on the mechanism of this host finding system (Lessells, 1985; Bernstein et al., 1989, 1991; Green \& Ayal, 1998).

In this study, host mortality was evaluated as the parasitism rate in an experiment with a discrete parasitoid generation. The experiment avoids the problem of grouping smaller experimental units from larger ones in a nested design. The parasitism rates thus differ from most experimental and field studies because of:

1. the random assignment of each sampling unit to one spatial scale. It makes the data spatially independent;

2. controlled sample size;

3. non-confusing roles of different environmental cues for parasitoids searching at different spatial scales.

Our study includes only the set of spatial scales where host cues are known to be perceived by the parasitoids, and the travel costs of parasitoids are low. Different searching cues are used at different scales, hence the design of our experiment should show the effects of spatial scales on parasitism rates.

The interactions between the solitary endoparasitoid Aphidius colemani Viereck (Hymenoptera: Aphidiidae), and its host, the green peach aphid Myzus persicae Sulzer (Homoptera: Aphididae), on greenhouse peppers Capsicum annuum L. were examined. A. colemani is a generalist aphid parasitoid commonly used in augmentative biological control of $M$. persicae and the cotton aphid, Aphis gossypii Glover, in vegetable greenhouses (e.g. Hofsvang \& Hågvar, 1975; Van Steenis, 1995). M. persicae is a pest of high economic importance, with wide geographic and host ranges (Van Emden et al., 1969). Pepper plants are heavily attacked in greenhouses by the green peach aphid.

\footnotetext{
* Corresponding author
} 


\section{MATERIAL AND METHODS}

The experiment was carried out in a $8 \times 3 \times 2 \mathrm{~m}$ greenhouse at Institut National de la Recherche Agronomique (I.N.R.A.), Antibes, France under controlled conditions (temperature $26 \pm$ $2{ }^{\circ} \mathrm{C}, \mathrm{RH} 65 \pm 25 \%$ ) allowing the effects of natural light that occurred in the region $\left(43^{\circ} \mathrm{N}, 8^{\circ} \mathrm{E}\right)$ between May - June. Two $1.6 \times 0.95 \times 1.15 \mathrm{~m}$ cages covered by nylon gauze were used for the experiment, each containing eight pepper plants, Capsicum annuum L. cultivar Sonar. Each plant $(54.2 \pm 0.5 \mathrm{~cm}$ tall) was potted in standard peat substrate, watered daily and fertilised weekly with $150 \mathrm{ml}$ of $18 \mathrm{~N}-6 \mathrm{P}-26 \mathrm{~K}$. At the onset of the experiment, the plants were 80-90 days old, and fruit maturation was beginning. The plants were equally spaced in a regular grid pattern, in which each plant created a discrete patch. The aphids used for the infestation of the pepper plants were a monoclonal population of Myzus persicae, reared at $22 \pm 2{ }^{\circ} \mathrm{C}$ and a 16L : 8D photoperiod on eggplant, Solamum melongena $\mathrm{L}$. cultivar Bonica. The parasitoids were originally collected on Aphis nerii Boyer de Fonscolombe in southern Brazil in 1982 and had been continuously reared on young eggplants infested by $M$. persicae in an insectary at I.N.R.A. at $16 \mathrm{~L}: 8 \mathrm{D}$ photoperiod and $23-25^{\circ} \mathrm{C}$. The parasitoids used in the experiments eclosed from mummies (parasitoid pupae within exoskeletons of dead aphids) kept separately in $0.4 \mathrm{ml}$ gelatine capsules under the same conditions as the stock culture.

Each pepper plant was infested by placing on its top leaves two pieces of eggplant leaves infested with a total of 30-40 aphids. The aphids on individual plants were then usually counted daily, and the rate of population increase was calculated by analysis of covariance (ANCOVA). The parasitoids were introduced when the ANCOVA indicated that the population growth rates of the aphids on individual plants had become exponential and they were similar in both cages (Jarošík et al., 1996). In that time, the aphid density ranged between 500-800 aphids per plant, but the difference in the total number of aphids between the two cages was only 253 aphids. Equal numbers of naïve (without any previous experience with egg laying), less than $24 \mathrm{~h}$ old male and female parasitoids were released uniformly in the cages above the pepper plants. The sex of the parasitoid was determined visually, and one female parasitoid released to approximately seventy aphids in each cage.

The evaluation of the relationship between aphid density and aphid mortality started by recording aphid densities on individual plants just before the parasitoids were released. The proportion of aphid mortality was assessed 12 days later, after all the parasitoids had died, but before the emergence of a new parasitoid generation. The proportion of aphid mortality was calculated by counting aphid "mummies", and then dividing the number of mummies by the original number of aphids before the parasitoid released. The proportion of aphid morality thus approximately corresponded to the successful parasitism. Different plants were used to calculate the proportion at different scales. Each of the eight plants in each cage was assigned to one of three scales: (1) plant, (2) shoot, and (3) leaf. Within the plants assigned to the shoot/leaf scale, one shoot/leaf was randomly assigned for evaluation. The range of aphid density increased from leaf to shoot to plant, so to control for increasing statistical significance with increasing range of density (Hails \& Crawley, 1992), from each cage three plants were assigned to the leaf and shoot scale, and two plants to the plant scale.

The data were evaluated by using ANCOVA with logit proportions of aphid mortality treated as the response variable, while the initial aphid density (loge transformed) attacked was treated as a covariate, the spatial scales (plant, shoot, and leaf) as the individual levels of a factor, and cage as a block effect.
The logit proportion of aphid mortality was expressed as $\ln$ $(p / 1-p)$, where $p$ was the proportion of the initial aphid density attacked. To check for "domed" mortality, the quadratic term for aphid density was added to the model. The statistics were weighted for sample size (initial number of aphids attacked at a particular scale) and the errors in the response variable assumed a binomial distribution (Cox \& Snell, 1990). McCullagh \& Nelder's (1989) correction for over-dispersion was used. In this procedure, the data were rescaled using a dispersion factor which was calculated by dividing Pearson's chi-square by the residual degrees of freedom. Calculation was made using general linear modelling in the commercial statistical package GLIM $^{\circledR}$ v. 4 (Crawley, 1993). The modelling started by regressing the logit proportions of aphid mortality on natural logarithms of initial aphid density with different intercept and different slope at plant, shoot and leaf scale, using cages as a blocking factor. The parameters of this model were inspected, and the least significant term was removed in a deletion test. If the deletion did not cause a significant increase in deviance, the term was removed. The deletion tests were repeated until only significant terms remained.

\section{RESULTS}

Mortality of the host was on average about $33 \%$. The mortality, however, varied with host density, and the pattern of mortality changed with the spatial scale.

The regression of host mortality on initial host density did not differ at the scale of shoot and leaf (deletion test: $F=0.078$, df $2 / 11, p=0.93)$. However, the slopes $(F=$ 15.71, $d f 2 / 13, p=0.0003)$ and the intercepts $(F=27.90$, df $1 / 12, p=0.0002$ ) of regression lines of host mortality on host density significantly differed between the plant scale, and the shoot and leaf scales pooled together. Host mortality was directly density dependent at the plant scale, and inversely density dependent at the shoot and leaf scales (Fig. 1). Consequently, increasing host density at the plant scale caused a significant increase in proportion of host mortality. However, at the shoot and leaf scales increasing host density caused a significant decrease in host mortality. The pattern of mortality was also significantly influenced by cage effects $(F=6.27, d f$ $1 / 12, p=0.03)$. The overall significance of the ANCOVA model with the significant regression slopes, intercepts, and cage effects was $p=0.001(F=10.17$, df $4 / 11)$, and the total explained variance by the model was $\mathrm{R}^{2}=$ $78.7 \%$.

The spatial differences in host mortality thus ranged from direct density dependent mortality to inverse density dependence, and mortality caused by the parasitoids tended to be direct density dependent at the plant scale, and negatively density dependent on smaller scales (shoot and leaf). Mortality on aphid density never appeared domed (deletion test from the minimal adequate model with all terms significant: $F=0.073$, df $2 / 9, p=0.93$ ).

\section{DISCUSSION}

There is ample field evidence that host mortality caused by parasitoid attack can be both directly density dependent and inversely density dependent. However, this is one of the first studies showing the change from inverse to direct density dependence within a particular 


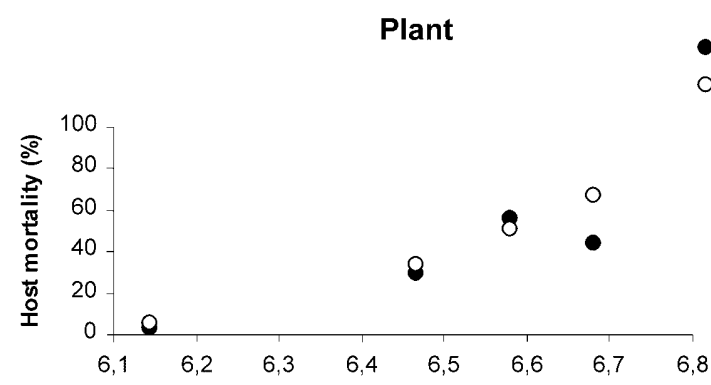

Shoot and leaf

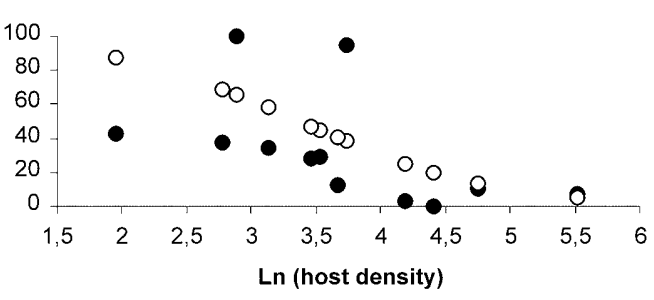

Fig. 1. Percentage mortality of the green peach aphid, Myzus persicae, caused by the parasitic wasp, Aphidius colemani, in relation to the natural logarithm of aphid density at the plant scale, and at the shoot and leaf scale. Fitted values are $\ln (p / 1-p)$ $=-43.32+6.60 \ln$ (aphid density) for the plant scale, and $\ln (p / I-p)=4.51-1.34 \ln$ (aphid density) for the shoot and leaf scales. The slopes and the intercepts are calculated from a model containing cages as a blocking factor. Their significance is $p=0.0003(F=12.74, d f 3 / 14)$, and the total explained variance by the slopes and intercepts is $\mathrm{R}^{2}=74.0 \%$. The fitted values of percentage mortality are obtained by a backward transformation of the logit weighted proportions of mortality, $\ln (p / I-p)$, in which $p$ is proportion of mortality.

set of local scales. The reason is that our data were collected differently from most reported in the literature. In our study, we randomly assigned each sampling unit to one spatial scale, attempting to generate spatially independent data points.

In the literature, a sampling unit usually corresponds to a small natural component of a habitat (e.g., a leaf of a plant), and larger scales are analysed by grouping together the smaller sampling units in a nested design (e.g., the data at the shoot scale are grouped together by the use of the leaves from the leaf scale, and the data at the plant scale by grouping together of the shoots from the same plant). However, such data is not spatially independent if not all units from the smaller scale are included in the larger scale. The reason is that environmental conditions within each nested group are likely to be unique, which can bias the analysis. For instance, host density on the smallest natural units, like individual leaves, are likely to vary. In addition, host densities are often more similar within intermediate units (e.g. shoots of a single plant) than between larger units (e.g. plants). The incomplete grouping of smaller units in a nested design, especially so if the number of sub-units grouped is small, can often result in density independent host mortality, a pattern most frequently found in field studies (Lessells, 1985; Stiling, 1987; Walde \& Murdoch, 1988). Moreover, as spatial scale increases in the nested design, the sample size declines (Heads \& Lawton, 1983; Rothman \& Darling, 1991), and the range of densities increases. Reducing sample size reduces the probability of detecting significant density dependence, but increasing the range of densities increases the likelihood of detecting density dependence. In general, the overall effect of changing spatial scale on the probability of detecting density dependence is then difficult to predict (Hails \& Crawley, 1992).

Parasitism tended to be directly density dependent at the plant scale, and negatively density dependent at the shoot and leaf scales. These results are consistent with previous literature surveys that found direct spatial density dependence in parasitism more frequent at an intermediate spatial scale ("whole plant or area 100-999 $\mathrm{cm}^{2}$ " or "several plants, trees, or area 1-10 m"", Stiling, 1987) than at a smaller or larger spatial scale. Similarly, inverse density dependence was found more frequently at smaller spatial scales corresponding to scales of egg masses through to branch levels (Walde \& Murdoch, 1988) than at larger scales. The result also seems be qualitatively consistent with explicit manipulative experiments that investigated scale dependent predation in aphid predators (Ives et al., 1993).

This work provides the first experimentally proven change from direct density dependence at the intermediate (plant) scale to inverse density dependence at the small (shoot and leave) scale. To date, there has been only one published case of switching from inverse to direct density dependence, concerning the solitary pteromalid parasitoid Mesopolobus incultus (Walker) in a field manipulative experiment (Norowi et al., 2000). This parasitoid, quite consistently with our results, exhibited inverse density dependence of parasitism rate at the small scale of the seedhead of the plant Plantago lanceolata L., but direct density dependence at the intermediate scale of the whole plant.

However, the pattern of density dependence in cages may differ from that in the field. The significant cage effects might suggest that micro-environment associated with each cage may lead to some interdependence among shoots, leaves and plants within a cage. It could weaken the value of our experimental approach using different plants to measure parasitism at each spatial scale to eliminate the spatial interdependence. This problem is partially solved by including the cages as a blocking factor in the statistical analysis, because the blocks filter out the unexplained part of variance due to the cages. Moreover, because the population growth rates of the aphids and the overall density of the aphids and the parasitoids in both cages were similar, we can also infer a similar distribution of aphids among plants and similar level of parasitoid interference in both cages. Consequently, the effect of different parasitoid's response to the different distribution of aphids in each cage should be small. 
In addition, the searching efficiency of parasitoids in cages likely differs from that of free-ranging parasitoids (Van Lenteren \& Bakker, 1976; Jones \& Hassell, 1988). Enclosing the parasitoids in a cage prevents natural dispersal after a period of oviposition, forcing the parasitoids to return to the same group of plants, whereas in natural field situations they might move longer distances in search of previously unvisited patches. However, if the arena is large enough so that the parasitoids respond to patches as discrete units in a way similar to their response to natural patches in the field, the experimental set-up does not qualitatively change the spatial pattern of parasitism (Jones \& Hassell, 1988). This is corroborated by previous investigations which have not found differences in the frequency of density dependence between laboratory and field studies (Stiling, 1987).

Our results thus suggest that it is difficult, but possible, to choose "the right scale" in testing for density dependence in parasitism (cf. Brown, 1989; Stiling, 1989). This is facilitated when the observed attack pattern can be elucidated by the different environmental cues adopted by the searching parasitoids (the same species) at different spatial scales. The study shows a change from direct to inverse density dependence of host mortality that is explicable by the different environmental cues used by the parasitoid at different spatial scales.

The aphidiid parasitoids first search for aphid infested host plants (Reed et al., 1970). Female Aphidius colemani show a preference for the host-plant complex on which it has been reared, but because $A$. colemani is a generalist, the preferences can be easy changed by subsequent foraging experiences (Storeck et al., 2000). Therefore, the fact that the parasitoids were reared on a different plant from that used in the experiments should play a minor role. The aphidiid parasitoids search preferentially the plants where the cues from the host-plant complex indicate aphid presence, and use honeydew secreted by the aphids as a kairomone for host location (e.g. Du et al., 1997) and as a cue for evaluating the number of aphids (Bouchard \& Cloutier, 1984; Ayal 1987). Because the level of honeydew also influences the number of parasitoid attacks (Shaltiel \& Ayal, 1998), aphidiids that attack Myzus persicae in greenhouse accumulate on pepper plants contaminated with honeydew (Hågvar \& Hofsvang, 1989). This accumulation can result in the observed direct density dependent host mortality at the scale of a plant.

After finding an infested plant, aphidiids search for hosts on the smaller scale of shoots and leaves (Ayal, 1987). An individual parasitoid may attack a lower percentage of available hosts at high than low aphid density (Hågvar \& Hofsvang, 1987). This can be explained by the fact that at least some species of aphidiids, perhaps including A. colemani (cf. Van Steenis et al., 1996; Driessen \& Bernstein, 1999) tend to leave the patch after a certain number of successful ovipositions, or after a certain number of encounters with previously attacked hosts. If so, this "count-down" mechanism (Iwasa et al., 1981; Driessen et al., 1995) will cause the proportion of para- sitised aphids to decrease rapidly with increasing aphid density (Shaltiel \& Ayal, 1998). Moreover, in dense aphid colonies in small patches, parasitoid interference (Hassell, 1971), and the alarm and escape reactions of aphids (Bowers et al., 1972) can cause decreases in host mortality with increasing host density. The inverse density dependence of host mortality at smaller scales than the plant thus becomes very likely.

The main result of our study is therefore a suggestion that resource location, assessment, and the searching of parasitoids are key factors for detecting spatial density dependence. However, we only demonstrate the effect of spatial scale on parasitism experimentally, and infer individual behaviour from the pattern of parasitism. Further work on the direct connection between individual behaviour and population dynamics, reflecting the action of field populations of parasitoids, is necessary.

ACKNOWLEDGEMENTS. We are much indebted to A. F. G. Dixon and A. P. Gutierrez for critical reading the manuscript. The work was supported by a grant of GAČR No. 206/97/0280 and MŠMT grant No. J13/98113100004.

\section{REFERENCES}

AYAL Y. 1987: The foraging strategy of Diaeretiella rapae. I. The concept of the elementary unit of foraging. J. Anim. Ecol. 56: 1057-1068.

Bernstein C., Kacelnik A. \& Krebs J.R. 1989: Individual decisions and the distribution of predators in a patchy environment. J. Anim. Ecol. 57: 1007-1026.

Bernstein C., KaCelniK A. \& Krebs J.R. 1991: Individual decisions and the distribution of predators in a patchy environment. II. The influence of travel costs and structure of the environment. J. Anim. Ecol. 60: 205-225.

BOUCHARD Y. \& ClOUTIER C. 1984: Honeydew as a source of host searching kairomones for the aphid parasitoid Aphidius nigripes (Hymenoptera: Aphidiidae), Can. J. Zool. 62: $1513-1520$.

Bowers W.S., Nault L.R., Webi R.E. \& Dutky S.R. 1972: Aphid alarm pheromone: Isolation, identification and synthesis. Science 177: 1121-1122.

Brown M.W. 1989: Density dependence in insect hostparasitoid systems: a comment. Ecology 70: 776-779.

Cox D.R. \& Snell E.J. 1990: Analysis of Binary Data. Chapman and Hall, London, 286 pp.

CRAWLEY M.J. 1993: GLIM FOR ECOLOGISTS. Blackwell Science, Oxford, $301 \mathrm{pp}$

Driessen G., Bernstein C., Alphen van J.J.M. \& Kacelnit A. 1995. A count-down mechanism for host search in the parasitoid Venturia canescens. J. Anim.Ecol. 64: 117-125.

Driessen G. \& Bernstein C. 1999: Patch departure mechanisms and optimal host exploitation in an insect parasitoid. J. Anim. Ecol. 68: 445-459.

Du Y.-J., Poppy G.M., Powell W. \& Wadhams L.J. 1997: Chemically mediated associative learning in the host foraging behavior of the aphid parasitoid Aphidius ervi (Hymenoptera: Braconidae). J. Insect Behav. 10: 509-522.

EMden Van H.F., Eastop V.F., Hughes R.D. \& Way M.J. 1969: The ecology of Myzus persicae. Annu. Rev. Entomol. 14: 197-270.

Getz W.M. \& Mills N.J. 1996: Host-parasitoid coexistence and egg-limited encounter rates. Am. Nat. 148: 333-347. 
Godfray H.C.J., Hassell M.P. \& Holt R.D. 1994: The population dynamic consequences of phenological asynchrony between parasitoids and their hosts. J. Anim. Ecol. 63: 1-10.

Godfray H.C.J. \& PaCala S.W. 1992: Aggregation and the population dynamics of parasitoids and predators. Am. Nat. 140: $30-40$.

GreEN R.F. \& AYAL Y. 1998: A simple Markov model for the assessment of host patch quality by foraging parasitoids. Oecologia 116: 456-466.

HÁgVar E.B. \& HofsVang T. 1987: Foraging by the aphid parasitoid Ephedrus cerasicola for patchily distributed hosts. Entomol. Exp. Appl. 44: 81-88.

HågVar E.B. \& Hofsvang T. 1989: Effect of honeydew and hosts on plant colonization by the aphid parasitoid Ephedrus cerasicola. Entomophaga 34: 495-501.

HaIls R.S. \& CRAWLeY M.J. 1992: Spatial density dependence in populations of a cynipid gall-former Andricus quercuscalicis. J. Anim. Ecol. 61: 567-583.

HAssell M.P. 1971: Mutual interference between searching insect parasites. J. Anim. Ecol. 40: 478-486.

Hassel M.P., May R.M., Pacala S. \& Chesson P.L. 1991: The persistence of host-parasitoid associations in patchy enviroments. I. A general criterion. Am. Nat. 138: 568-583

HASSELl M.P. \& Southwood T.R.S. 1978: Foraging strategies of insects. Annu. Rev. Ecol. Syst. 9: 75-95.

Heads P.A. \& Lawton J.H. 1983: Studies on the natural enemy complex of the holly leaf-miner: the effects of scale on the detection of aggregative responses and the implications for biological control. Oikos 40: 267-276.

Hochberg M.E. \& LAwton J.H. 1990: Spatial heterogeneities in parasitism and population dynamics. Oikos 59: 9-14.

HofsVang T. \& HågVar E.B. 1975: Fecundity and oviposition period of Aphidius platensis Brethes (Hym.: Aphidiidae) parasitizing Myzus persicae Sulz. (Hom.: Aphididae) on paprika. Norw. J. Entomol. 22: 113-116.

IWASA Y., Higashi M. \& YamamuRa N. 1981: Prey distribution as a factor determining the choice of optimal foraging strategy. Am. Nat. 117: 710-723.

IVES A.R. 1992: Density-dependent and density-independent parasitoid aggregation in model host-parasitoid systems. $\mathrm{Am}$. Nat. 140: 912-937.

Ives A.R., Kareiva P. \& Perry R. 1993: Response of a predator to variation in prey density at three hierarchical scales: lady beetles feeding on aphids. Ecology 74: 1929-1938.

JaRošík V., HonĚK A., LapChin L. \& Rabasse J.-M. 1996: An assessment of time varying rate of increase of the green peach aphid, Myzus persicae: its importance in IPM of commercial greenhouse peppers. Ochr. Rost. (Plant Protect.) 32: 269-276.

Jones T.H. \& Hassell M.P. 1988: Patterns of parasitism by Tribliographa rapae, a cynipid parasitoid of the cabbage root fly, under laboratory and field conditions. Ecol. Entomol. 13: 309-317.

LeNTEREN VAN J.C. \& BaKkeR K. 1976: Functional response in invertebrates. Neth. J. Zool. 26: 567-572.
Lessells C.M. 1985: Parasitoid foraging: should parasitism be density dependent? J. Anim. Ecol. 54: 27-41.

McCullagh P. \& Nelder J.A. 1989: Generalized Linear Models. Chapman and Hall, London, $198 \mathrm{pp}$

Murdoch W.W. \& Stewart-Oaten A. 1989: Aggregation by parasitoids and predators: effect on equilibrium and stability. Am. Nat. 134: 288-310.

Murdoch W.W., Briggs C.J., Nisbet R.M., Gurney W.S.C. \& Stewart-Oaten A. 1992: Aggregation and stability in metapopulation models. Am. Nat. 140: 41-58.

Norowi H., Perry J.N., Powell W. \& Rennolls K. 2000: The effect of spatial scale on interactions between two weevils and their parasitoid. Ecol. Entomol. 25: 188-196.

PaCala S. \& Hassell M.P. 1991: The persistence of host parasitoid associations in a patchy environment. II. Evaluation of field data. Am. Nat. 138: 584-605.

ReEd D.P., Feeny P.P. \& Root R.B. 1970: Habitat selection by the aphid parasite Diaeretiella rapae (Hymenoptera: Braconidae) and hyperparasite Charips brassicae (Hymenoptera: Cynipidae). Can. Entomol. 102: 1567-1578.

Rohani P., Godfray H.C.J. \& Hassell M.P. 1994: Aggregation and the dynamics of host-parasitoid systems: a discrete generation model with within-generation redistribution. Am. Nat. 144: 491-509.

Rothman L.D. \& DarLing D.C. 1991: Spatial density dependence: effects of scale, host spatial pattern and parasitoid reproductive strategy. Oikos 62: 221-230.

Shaltiel L. \& Ayal Y. 1998: The use of kairomones for foraging decisions by an aphid parasitoid in small host aggregations. Ecol. Entomol. 23: 319-329.

STEENIS VAN M.J. 1995: Evaluation of four aphidiine parasitoids for biological control of Aphis gossypii. Entomol. Exp. Appl. 75: 151-157.

Steenis van M.J., El-Khawass K.A.M.H., Hemerik L. \& LenTEREN VAN J.C. 1996: Time allocation of the parasitoid Aphidius colemani (Hymenoptera: Aphidiidae) foraging for Aphis gossypii (Homoptera: Aphidae) on cucumber leaves. $J$. Insect Behav. 9: 283-295.

Stephens D.W. \& Krebs J.R. 1986: Foraging Theory. Princeton University Press, Princeton, 381pp.

STILING P.D. 1987: The frequency of density dependence in host-parasitoid systems. Ecology 68: 844-856.

StiLing P.D. 1989: Density dependence - a reply to Brown. Ecology 70: 779-783.

Storeck A., Poppy G.M., Emden van H.F. \& Powell W. 2000: The role of plant chemical cues in determining host preference in the generalist aphid parasitoid Aphidius colemani. Entomol. Exp. Appl. 97: 41-46.

TAYLOR A.D. 1993: Heterogeneity in host-parasitoid interactions: "Aggregation of risk" and the $\mathrm{CV}^{2}>1$ rule". Trends Evol. Ecol. 8: 400-405.

Walde S.J. \& Murdoch W.W. 1988: Spatial density dependence in insect parasitoids. Annu. Rev. Entomol. 33: 441-466.

Received November 20, 2000; revised February 8, 2001; accepted June 4, 2001 